\title{
O ENSINO DE CLIMATOLOGIA NO ENSINO FUNDAMENTAL: A MEDIAÇÃO DE ATIVIDADES DE CONFECÇÃO DE DESENHOS DE PAISAGENS CLIMÁTICAS.
}

\author{
Hemerson Souza Gomes ${ }^{(a)}$ Ana Cláudia Ramos Sacramento ${ }^{(b)}$
}

(a) Departamento de Geografia/Faculdade de Formação de Professores, Universidade do Estado do Rio de Janeiro, Email: hemerson89@ hotmail.com.

(b) Departamento de Geografia/Faculdade, Faculdade de Formação de Professores, Universidade do Estado do Rio de Janeiro, Email: anaclaudia.sacramento@hotmail.com

EIXO: GEOGRAFIA FÍSICA - CURRÍCULO, FORMAÇÃO E PRÁTICAS DE ENSINO

\begin{abstract}
Resumo
Este trabalho objetiva analisar a mediação do ensino de clima a partir da utilização do conceito de paisagem por meio da construção de desenhos feito pelos próprios alunos desenvolvidas por estudantes de turmas de $6^{\circ}$ ano, num colégio da rede privada no município de Magé-RJ. Como metodologia trabalhou-se com a pesquisa qualitativa, pois os estudantes se tornam sujeitos da aprendizagem, ou seja, participativos e autores no processo de construção do conhecimento sobre o clima e os fenômenos climáticos. A mediação foi feita com base na concepção teórica do estudo de paisagem, ensino de geografia e o ensino de climatologia. O resultado foi a leitura sobre o clima na percepção cotidiana nos trabalhos apresentados em sala, com o intuito de levar os alunos a saberem agir mediante a fenômenos climáticos, identificando-os em seu dia a dia e sabendo posicionar-se de forma consciente, reflexiva e crítica perante a relação entre natureza e homem.
\end{abstract}

Palavras chave: Climatologia, ensino de geografia, paisagem climática, desenhos, Magé.

\section{Introdução}

A geografia como disciplina escolar tem grande relevância para a educação básica, já que possibilita uma discussão sobre a leitura crítica espacial com o objetivo de promover e formar cidadãos conscientes de seu espaço, bem como na compreensão das transformações espaciais a partir da interação homem e natureza. O ensino crítico mediado em sala de aula pelo docente permite que os estudantes analisem, compreendam e transformem seu espaço vivido, sendo assim um processo significativo de ensinagem, conforme salientado por CAVALCANTI (2009), AFONSO; ARMOND (2009) e CASTELLAR (2014). Pensar a análise dos fenômenos físico-naturais permite também entender os seus diferentes aspectos como no caso, do ensino de clima, trazendo a importância não somente para uma melhor leitura do espaço físico-natural, mas a leitura também do meio social, que sofre influências diretas do clima. Por isso, a pertinência de um ensino que capacite os estudantes a se apropriar desse conhecimento que os permita desenvolver leitura do lugar e da sociedade onde vivem AFONSO; ARMOND (2009). 
No processo de ensinar e aprender geografia, é preciso ser levado em consideração o saber prévio que os estudantes possuem. Saber esse que advém das experiências que cada indivíduo possui, sendo empírico. Nessa perspectiva, a paisagem do lugar torna-se fundamental para a análise e compreensão do espaço e facilitação do ensino de clima conforme Fortuna (2011). Esta paisagem pode abranger uma porção do espaço dotado da interação entre elementos natuais e antrópicos, segundo BERTRAND (1971).

Sendo assim, esse trabalho objetiva compreender como a atividade dos desenhos de paisagens climáticas feitos pelos estudantes do sexto ano do ensino fundamental de escola privada no município de Magé pode contribuir para a aprendizagem do clima em sala de aula. Esta pesquisa está inserida no projeto de pesquisa "Leituras sobre as espacialidades das cidades e suas representações na sala de aula", financiada pela FAPERJ - Fundação Carlos Chagas Filho de Amparo à Pesquisa do Estado do Rio de Janeiro, período 2016-2018.

O texto está dividido em quatro momentos: o primeiro trata de pensar o clima usando os desenhos para mediação das aulas de Geografia; o segundo apresenta a metodologia trabalhada para desenvolver a atividade a ser realizada com os estudantes; no terceiro a análise da atividade de clima realizada com os alunos; no quarto as discussões do resultado e a conclusão da atividade.

\section{A importância dos conceitos clima e paisagens nas aulas de Geografia.}

É relevante não só o trabalho com os conceitos fundamentais da geografia no processo de ensino, como também se faz necessário o próprio entendimento desses conceitos. O estudante precisa apropriar-se desse conhecimento teórico antes de começar a articular as áreas de conhecimento, constituindo assim parte indispensável do processo de ensino da geografia física.

A climatologia trata dos padrões de comportamento da atmosfera em suas interações com as atividades humanas e com a superfície terrestre no decorrer de um período de tempo muito longo (MENDONÇA; DANNI-OLIVEIRA, 2007). No âmbito geográfico, a compreensão do clima está ligada ao entendimento da nossa realidade social e histórica e, por conseguinte, do ambiente no qual vivemos (DENIZART, 2011, p.02).

É necessário a compreensão de clima e paisagem para que consigam analisar de forma efetiva a organização do espaço. Além disso, para aprender esses conceitos de forma separada é preciso saber analisá-los também em sua complementaridade com a sociedade que neles se inserem.

A ciência geográfica aplicada em sala de aula trabalha com a dialética existente entre natureza e sociedade. Assim, faz-se importante o ensino de geografia física, para que o aluno entenda o meio natural e seu funcionamento para entender a atuação do homem nesse espaço. Desta forma, ele pode se apropriar 
de conhecimentos relativos ao tempo e clima, à geomorfologia, aos recursos hídricos, ao solo e à cobertura vegetal.

A climatologia possui um papel importante na sociedade. Compreende o clima, segundo Ayoade (2010); como um importante elemento do ambiente natural, pois atua diretamente como os processos de formação do relevo, pedologia e desenvolvimento das paisagens terrestres. Fornecendo os principais fatores que permitem a vida da humanidade que são o ar e água; e todos os outros que desencadeiam a partir desses (BARBOSA; OLIVEIRA, 2012, p.111).

O ensino de clima assume um papel fundamental para formação do indivíduo no entendimento de seu espaço. A climatologia é uma área que se faz como agente essencial para a compreensão da espacialização e organização social, uma vez que a ação do clima se relaciona diretamente com o solo, a vegetação, a economia, turismo, etc. Logo, sua compreensão é de suma importância para formar um indivíduo consciente de seu espaço.

Por conseguinte, ao trabalhar com a climatologia seja de forma conceitual ou em análises de elementos ou fatores; o conceito de paisagem passa a fazer parte direta e significativa neste processo. Trabalhar o clima sem utilizar a paisagem torna-se inviável para uma compreensão mais significativa, visto que são conceitos que se complementam.

Para a geografia, o conceito de paisagem abrange o clima, o lugar e as transformações pelo qual esse espaço tem passado. A paisagem contempla inúmeras concepções acerca do seu significado e de formas diferentes. Pode ser natural, humanizada; pode também ser utilizada por diferentes profissionais, assim como pela mídia mesmo que seja objeto de estudo dos geógrafos, porém, sempre com a possibilidade de variados usos e abordagens.

[...] tanto a paisagem quanto o espaço resultam de movimentos superficiais, uma realidade de funcionamento unitário, um mosaico de relações, de formas, funções e sentidos [...] paisagem artificial é a paisagem transformada pelo homem, enquanto grosseiramente podemos dizer que a paisagem natural é aquela ainda não moldada pelo esforço humano. Se no passado havia a paisagem natural, hoje essa modalidade praticamente não existe mais. Se um lugar não é fisicamente tocado pela força do homem, ele todavia é objeto de preocupação e intenções econômicas ou políticas, (SANTOS, 1994, p. 64).

$\mathrm{O}$ autor, no trecho anterior, define o conceito de paisagem a partir de seus movimentos e a realidade que existe nesse mesmo espaço, ressaltando suas classificações entre paisagens transformadas ou naturais, sendo a última praticamente não existente, uma vez que praticamente todo o espaço foi de alguma forma tocado ou sofre influência direta ou indireta do homem. Por outro lado, Bertrand (1971) afirma que a paisagem é uma combinação instável de elementos físicos, biológicos e antrópicos que reage de forma dialética uns com os outros, fazendo de cada paisagem um espaço único e esses elementos indissociáveis. 
Ainda nessa perspectiva, é também importante a discussão referente às representações sociais que os alunos possuem em relação ao conceito de paisagem e do clima, usando variadas vezes nas aulas de Geografia. Segundo Cavalcanti (2012), para trabalhar com a formação de conceitos com os alunos, é imprescindível entender quais são as representações sociais que os mesmos constroem ao redor desses conceitos:

[...] ao expressar o conhecimento cotidiano do aluno, ou seja, o que ele já conhece e que é compartilhado socialmente, as representações sociais ajudam a superar o relativismo e o subjetivismo no ensino. Em segundo lugar, são conhecimentos ainda em construção, cuja referência inicial é a imagem mental. Assim, utilizar esse recurso metodológico permite o trabalho com conhecimentos ainda não conscientes e não verbalizados. As representações sociais estão no nível do conhecimento vivido, que contém elementos de um conceito já potencialmente existente nos alunos, que pode ser tomado como parâmetro de aprendizagem significativa (CAVALCANTI, 2012, p.48).

Ao iniciar a mediação do ensino de clima em sala, a paisagem se faz como fator importante para o entendimento do assunto e seus inúmeros tipos e paisagens climáticas. As paisagens sejam do lugar ou globais são essenciais para a abordagem de tipos de climas e tempo meteorológicos. Nesse sentido, a junção de paisagem geográfica e climatologia formam uma dupla conceitual necessária na facilitação do processo de ensino de clima.

Nesse sentido paisagem climática é entendida como o espaço composto por elementos físicos, biológicos e antrópicos que estão diretamente relacionados ao clima, geralmente, representados na paisagem pela figura dos elementos e fatores climáticos, ou seja, um espaço que nos remeta a identicar em sua composição e interação de seus elementos o tempo meteorológico ou a clima de um dado lugar.

Os temas ensinados sem o uso de imagens serão sempre muito abstratos, exceto aqueles que são parte do cotidiano dos alunos. O uso das paisagens climáticas por imagens e figuras serão instrumentos de grande eficácia principalmente quando forem trabalhados climas de outras partes do globo os quais os alunos não têm acesso ou conhecimento.

\section{Metodologia qualitativo no ensino de Geografia}

Os estudantes foram os sujeitos da pesquisa e, a partir da compreensão da realidade destes, ocorreu a definição da atividade, partindo das representações sobre a paisagem.

Os pesquisadores que fazem uso da abordagem qualitativa estão interessados no modo como os diferentes sujeitos dão sentido às suas vidas e estão comumente a questionar os sujeitos da investigação como interpretam as suas experiências e o modo como estruturam o mundo social em que vivem BOGDAN; BIKLEN (1994). 


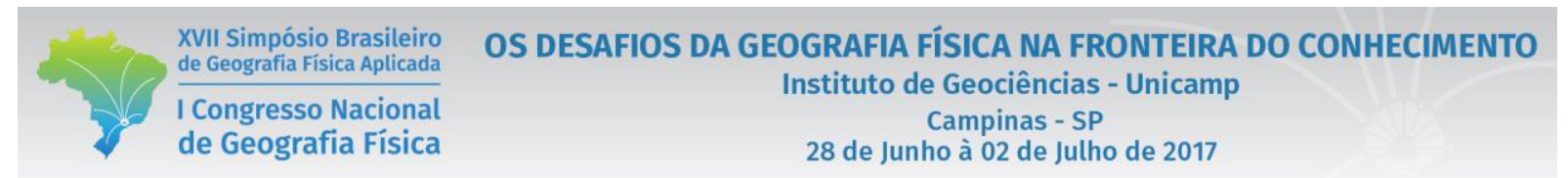

A pesquisa qualitativa, como denomina, tem como objetivo a qualidade e não é inferida por números. A ideia é compreender ou interpretar uma dada realidade do indivíduo, no nosso caso, é compreender as representações dos alunos em um determinado grupo e realidade. A partir disso, entender como se constrói a percepção sobre um determinado lugar. A ideia é a dinâmica de compreensão da realidade pelo indivíduo.

Os aportes teóricos-metodológicos da pesquisa qualitativa contribuem no processo de apreensão das interpretações e representações construídos pelos sujeitos (estudantes das escolas) com seus espaços de vivência e experiência, permitindo perceber que a produção do espaço é, ao mesmo tempo, material e simbólica.

O trabalho foi realizado no Colégio Grupo Potência de Ensino, no primeiro distrito do município de Magé, localizada na região metropolitana do Estado do Rio de Janeiro e também parte integrante da Baixada Fluminense (figura 1); escolhida assim para ser o referencial espacial da pesquisa em questão. É uma Instituição de ensino particular que funciona em três turnos (manhã, tarde e noite), possui cerca de 400 alunos matriculados.

Os participantes do estudo foram os alunos do sexto ano do ensino fundamental. As atividades práticas contaram com a participação de cerca de 40 alunos, com faixa etária entre 09 e 14 anos. Esses alunos são todos residentes do município de Magé e em geral são alunos de classe média. A turma possui um perfil falante, agitado e curioso. Seus integrantes também são participativos e proativos no que se refere à participação nas aulas e atividades.

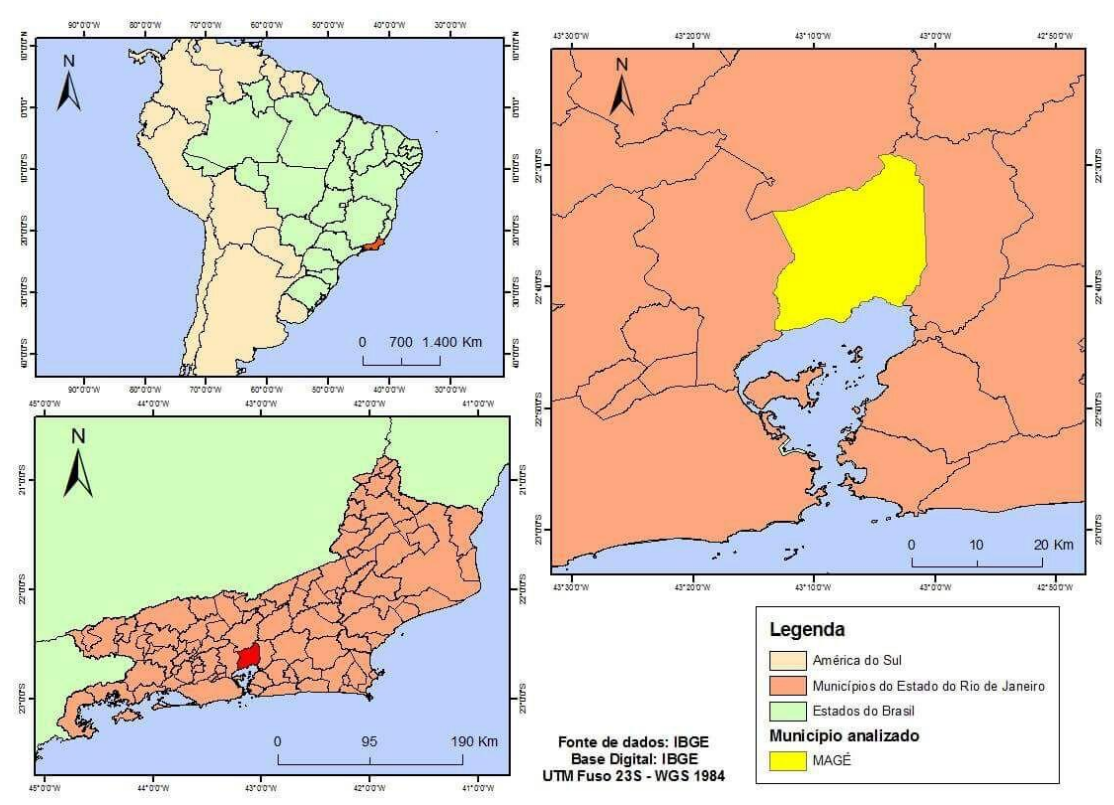

Figura 1 - Mapa de Magé no Estado do Rio de Janeiro 
Várias atividades foram desenvolvidas ao longo do trabalho, mas será apresentada a atividade referente à construção e debate sobre os desenhos ocorrida nos seguintes passos: 1) após discussão inicial sobre a importância do clima no dia a dia, cada aluno ficou responsável por pensar numa paisagem que se relacionasse ao clima; 2) depois, foi dado a cada um, uma folha de papel em branco, para que desenhasse uma paisagem que tivesse relação direta com o clima ou qualquer imagem que tivesse referência com a climatologia; 3) os estudantes apresentaram os desenhos e explicaram porque fizeram desta forma; 4) discussão mediada com os estudantes sobre a importância de pensar o clima por meio dos desenhos, bem como as principais características, tipos e formas conceitual sobre o tema tratado.

\section{Os desenhos confeccionados pela turma de $6^{\circ}$ ano do ensino fundamental desenvolvendo a leitura e análise da paisagem.}

Toda a pesquisa em sala foi mediada considerando o conhecimento prévio dos estudantes e seu contexto social, deixando assim o processo de ensinagem mais completo e significativo, pois todos os sujeitos contribuíram para a construção desse conhecimento segundo CASTELLAR (2014).

Além disso, ao utilizar as paisagens cotidianas dos estudantes para tornar o conhecimento mais significativo e contextualizado, como tornar a cidade um objeto de estudo, pode ser uma possibilidade de desenvolver a análise do clima e onde influencia dentro das paisagens que são parte dos cotidianos dos indivíduos envolvidos no processo de ensino aprendizagem, CASTELLAR; VILHENA (2012).

O uso do desenho foi fundamental para a mediação do ensino de clima dentro de sala. Ensinar geografia de forma geral sem o uso de imagens e sem os desenhos dificulta o processo de ensino, visto que a imagem constitui um instrumento simples, porém relevante no processo de ensinagem. As imagens e os desenhos permitem que os alunos vejam e percebam o meio que é ensinado e não apenas imaginem, aproximando-os dos conteúdos abordados em diferentes escalas e quando a imagem é produzida pelo estudante leva o professor próximo ao lugar onde vivem, entendendo assim seu conhecimento prévio, a partir do desenho que produziram.

o desenho é consciência de um universo pessoal, resultado de experiências mentais e emotivas, essenciais nos processos criativos. Perceber o espaço, compreender as relações intrínsecas da sociedade, os problemas e as possíveis soluções presentes nas aulas de Geografia que podem ser potencializadas com atividades de representação e desenho, (PEREIRA; DIAS, 2015, p.238). 
Na mediação do ensino de geografia, o uso de desenhos é importante no processo de ensino, mas não deve ocorrer de forma desinteressada. Os desenhos precisam ser utilizados em conexão direta com os conteúdos que serão ensinados. O professor deve mediar de forma a usar as figuras ou os desenhos e induzir os alunos a identificar os fenômenos, a partir dessa análise. Como destacam Pereira; Dias (2015, p.225): "Os desenhos são formas de representar experiências vividas, realidade social, raciocínio e visão de mundo".

Em concordância com as autoras, o uso de imagens e desenhos na mediação do ensino de geografia é fundamental, entretanto só tendo coerência com o conteúdo que o professor pretende ensinar. Os desenhos de paisagens auxiliam de forma positiva na compreensão de clima, facilitando a compreensão por parte dos discentes.

O clima não pode ser trabalhado somente visando o lugar, mas também deve ser aprendido de forma geral desde o clima local até as características das zonas térmicas do planeta, o que envolve diversos outros países e características. Sem o trabalho com imagens para ilustrar esses tantos lugares, os alunos teriam apenas o uso da imaginação ou o que já viram ou ouviram sobre o tema.

Sejam lugares ao redor do globo ou o lugar de vivência de cada um. Utilizar figuras e desenhos que retratam paisagens, principalmente, do lugar que os estudantes experimentam traz ao processo de ensino riqueza de detalhes e maior pontencial de entendimento. Compreender o que não se vê torna-se muito abstrato.

A partir de toda a análise feita nessa pesquisa, dos trabalhos apresentados pelos estudantes, das atividades concluídas, dos debates e discussões; o uso da imagem e dos desenhos se mostraram essencial nesse processo de ensino e aprendizagem, dando aos alunos a visão do novo ou mesmo do antigo, mas sobre novos ângulos a possibilidade de se por de forma lúcida dentro do processo e assim apreender melhor o proposto.

Observou-se a necessidade de pensar essa atividade (os desenhos de paisagens ligadas ao clima) para a turma do sexto ano do ensino fundamental, porque apresentam idades entre 9 e 14 anos, sendo, portanto, crianças e adolescentes. A abordagem sobre seus conhecimentos empíricos precisou respeitar sua capacidade cognitiva e a maturidade correspondente aos componentes da turma. A análise comprovou que não diferente do ensino médio, pois também confundem clima com tempo meteorológico. Os desenhos mostraram paisagens cotidianas e comuns do lugar e região onde vivem. Os alunos não encontraram dificuldades para pensar em tais paisagens, muito menos em associar ao lugar onde vivem. 


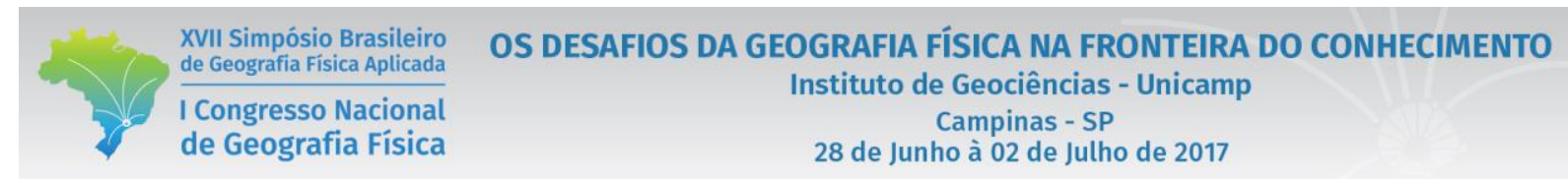

Esses desenhos foram pensados e feitos pelos estudantes e apresentados junto a um seminário sobre qual abordavam o clima do lugar onde vivem, como percebem esse clima e onde no meio social o clima transforma ou modifica suas ações.

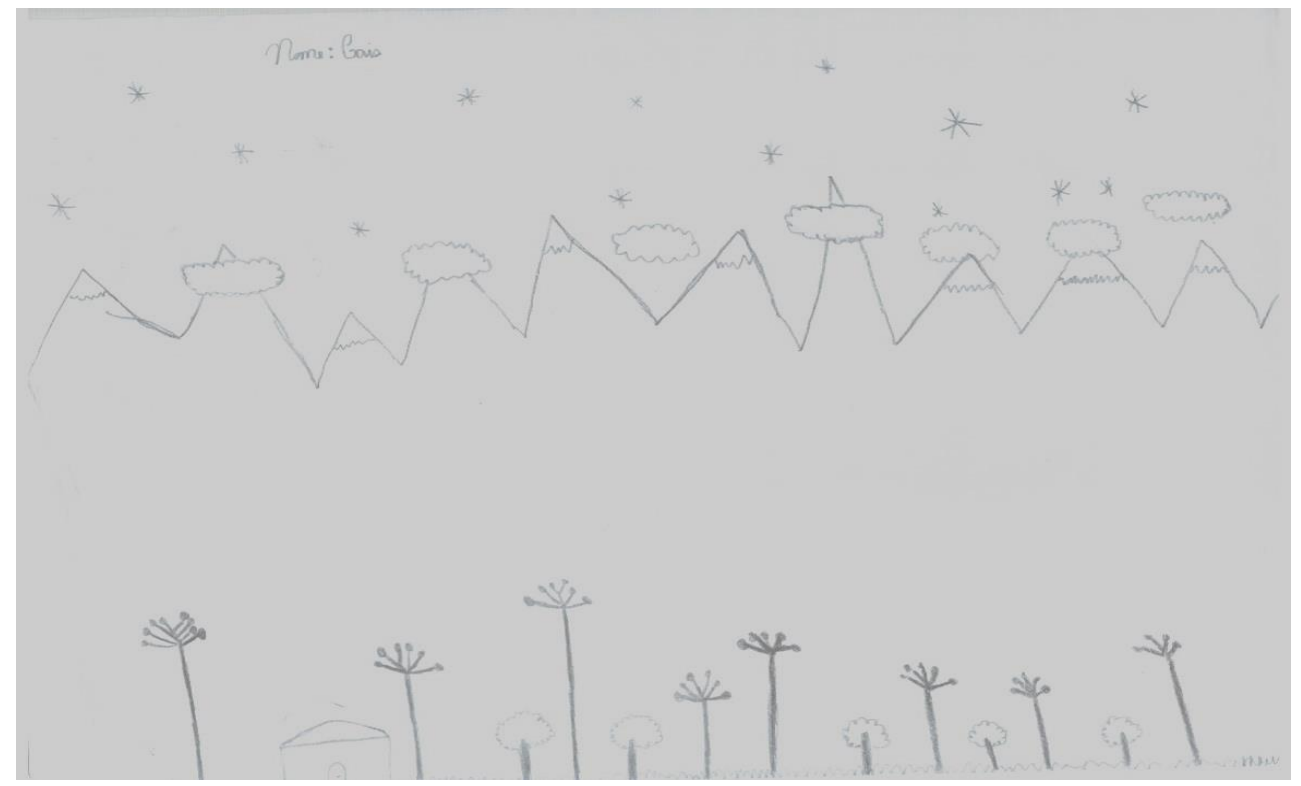

Figura 2 - Colinas e Araucárias desenhados pelo aluno A do $6^{\circ}$ ano do ensino fundamental.

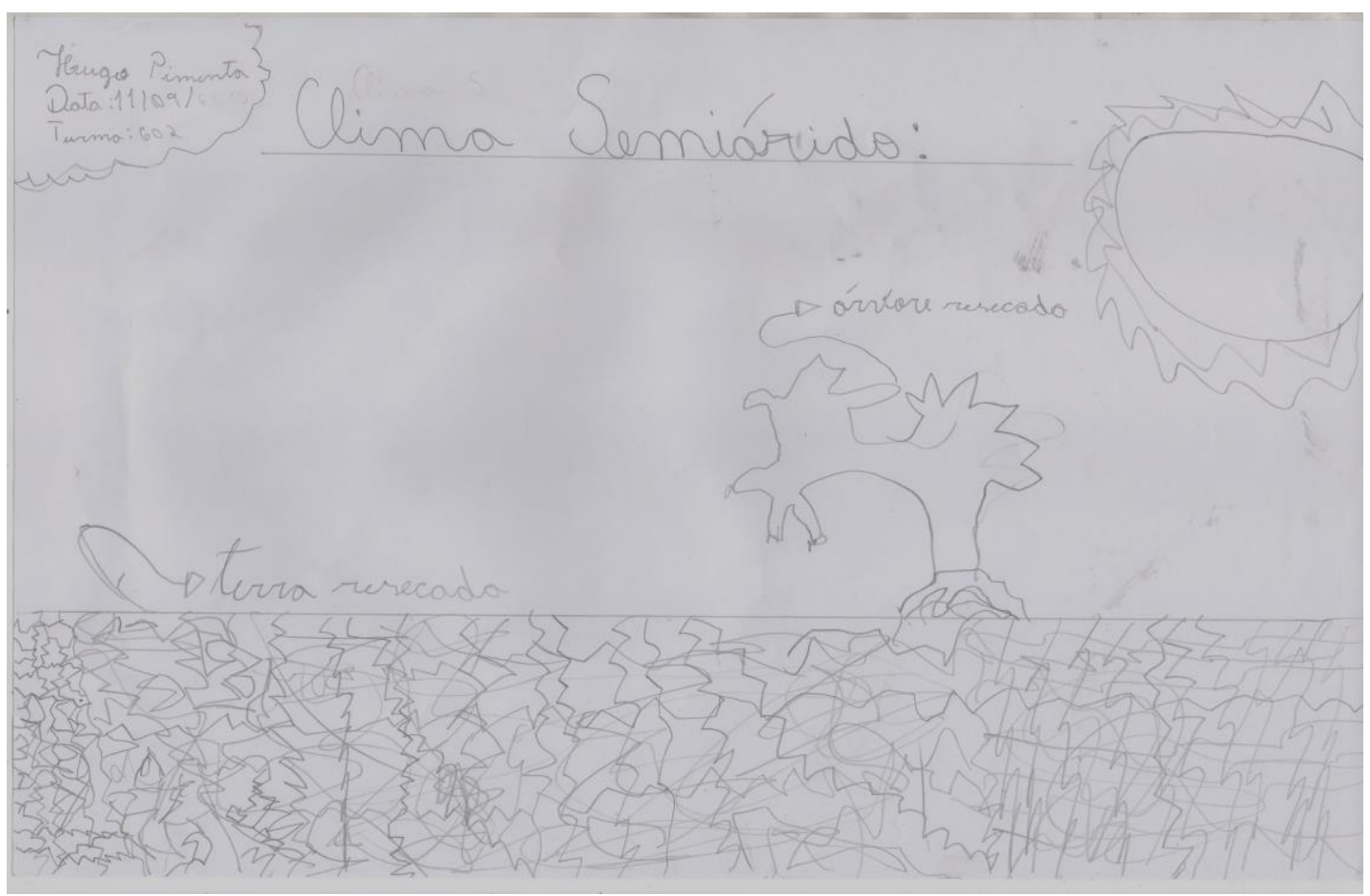

Figura 3- Semiárido nordestino desenhado pelo aluno B do $6^{\circ}$ ano do ensino fundamental 


\section{OS DESAFIOS DA GEOGRAFIA FÍSICA NA FRONTEIRA DO CONHECIMENTO \\ Instituto de Geociências - Unicamp \\ Campinas - SP \\ 28 de Junho à 02 de Julho de 2017}

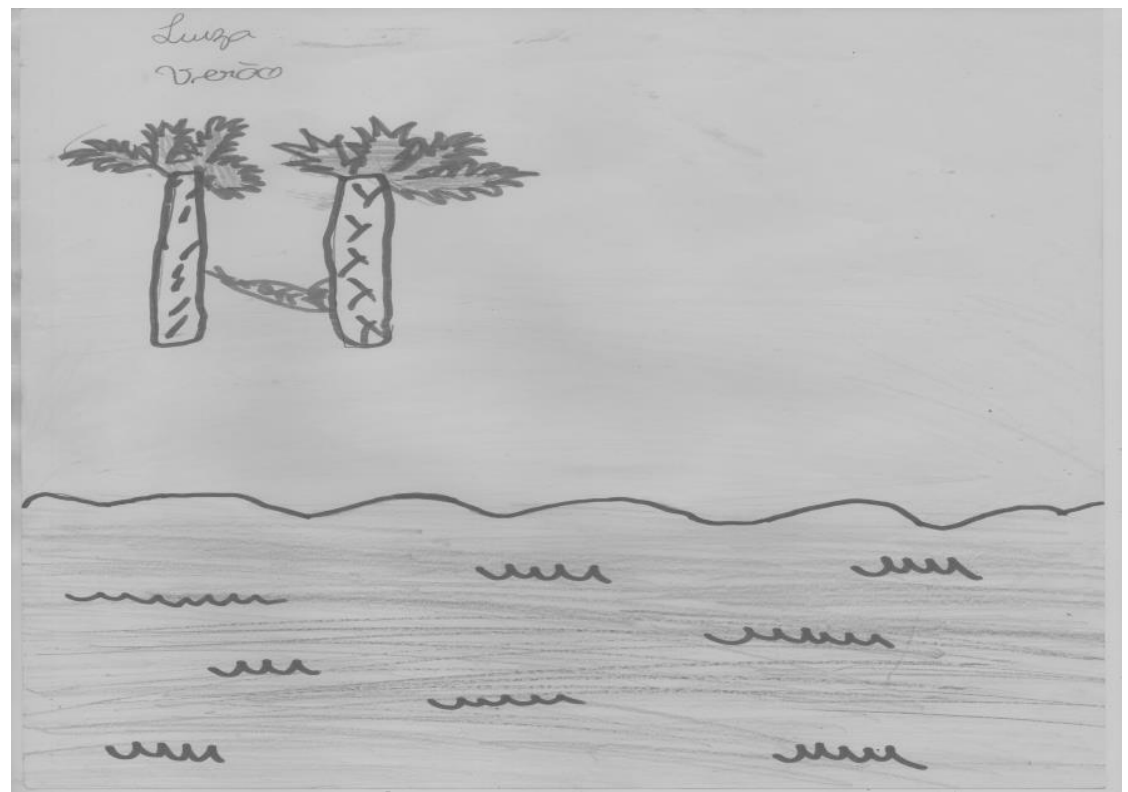

Figura 4 - Praia em dia ensolarado desenhado pelo aluno $\mathrm{C}$ do $6^{\circ}$ ano do ensino fundamental

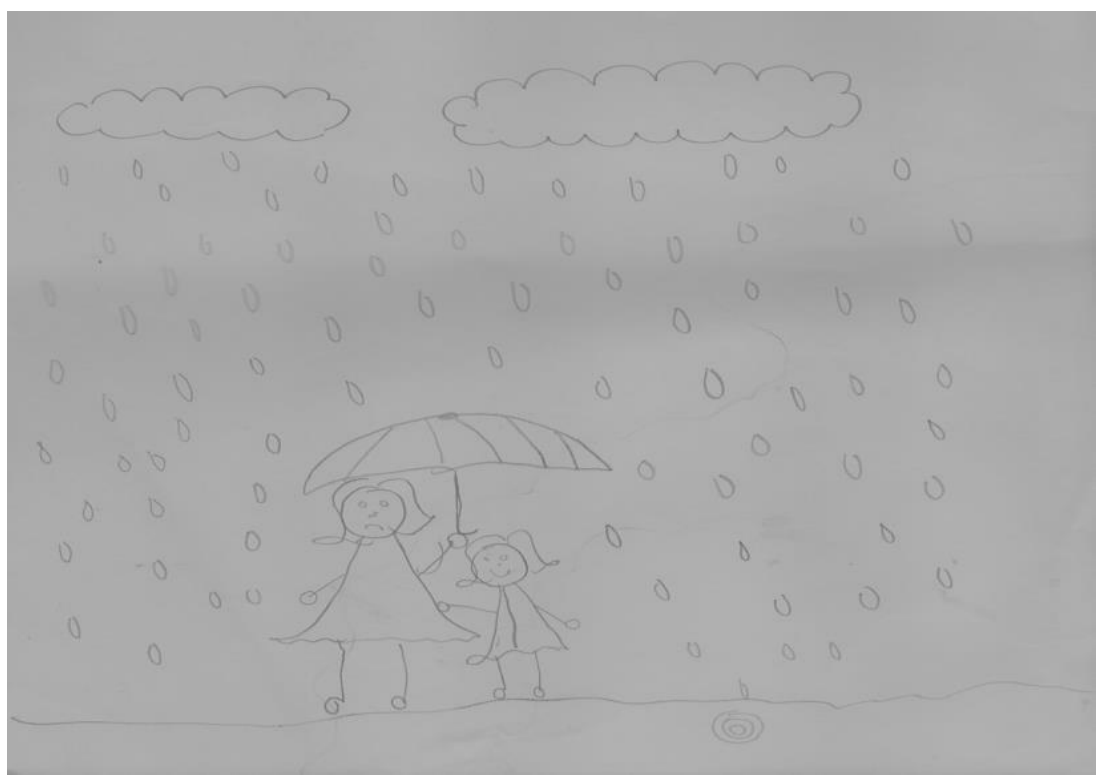

Figura 5 - Dia chuvoso desenhado pela aluna $\mathrm{E}$ do $6^{\circ}$ ano do ensino fundamental

A figura 2 retrata colinas e a mata de araucárias. A princípio, uma paisagem tipicamente sulista e relacionada ao clima subtropical, porém também presente na região serrana do Rio de Janeiro que inclui os municípios de Petrópolis, Teresópolis e Nova Friburgo; cidades que são limítrofes ou próximas ao município de Magé. Cabe ressaltar que o aluno retratou uma paisagem próxima e não uma área com relação direta a sua cidade. O que traz para a análise que os estudantes de forma empírica têm referências também de cidades vizinhas ou áreas mais distantes, o que enriquece a pesquisa e aponta para um saber 
prévio que não se limita ao espaço vivido. Logo, cabe a análise também da figura 3 que vai ainda mais além, onde o aluno utiliza outra escala de análise trabalhando com outra macrorregião brasileira, ao representar a caatinga e o sertão nordestino.

Os desenhos expostos dos alunos nas figuras 4 e 5 retratam perfeitamente situações comuns e cotidianas do morador da região metropolitana do Estado do Rio de Janeiro. Uma das imagens retrata um dia ensolarado na praia ligado ao verão carioca e a outra um dia chuvoso. Ambos os desenhos se relacionam ao verão carioca, onde é comum termos praias lotadas e noticiadas, além de alto índice de chuvas que ocorrem principalmente na estação de verão, pelo alto índice de calor e umidade da região metropolitana do Estado do Rio de Janeiro. No entanto, a relação das imagens com o clima e as estações do ano foram trabalhadas nos debates em classe de aula.

Os desenhos mostram cenas corriqueiras e cotidianas do corpo discente e de fato tem ligação com o clima. Tendo os desenhos como referência, foi desenvolvida a aula expositiva para abordar a diferença entre tempo e clima, especificação entre fatores e elementos climáticos, além de apontar para a influência da climatologia no cotidiano de cada um. Foi relevante a utilização de imagens projetadas (aparelho retroprojetor), além dos desenhos dos estudantes para quebrar a abstração de alguns conceitos e aproximálos do tema.

\section{Considerações finais}

O ensino de geografia com seus fenômenos físicos-naturais e paisagens tem sido muito mais difundidos pela mídia e internet do que dentro das salas de aula, além de se fazer importante a observação de que tem sido feita pelos sistemas de comunicação com inúmeros equívocos conceituais. Desta forma, se faz necessário que os docentes busquem desenvolver em suas aulas as discussões referentes ao ensino da Geografia Física, uma vez que os fenômenos se manifestam diariamente no espaço geográfico.

Uma forma de pensar tradicional, mas que ainda é pertinente para ensinar esta disciplina está associada ao desenvolvimento dos desenhos pelos alunos o qual demonstrou o conhecimento prévio destes estudantes sobre clima, trazendo informações importantes em cada elemento e fator climático desenhado pelos mesmos.

Essa atividade pontencializou a compreensão do ensino de clima, a partir de seus trabalhos. Esses desenhos possibilitaram uma mediação sobre a importância de entender os conceitos e a leitura que os estudantes fazem da paisagem, assim como a leitura do espaço que eles próprios experimentam, uma vez que perceberam pelos desenhos que compreendiam seu lugar, mas de forma empírica. Só restando ao professor mediar e levá-los ao conhecimento escolar e científico, porém a partir dos desenhos e conhecimentos que expressaram. 
Assim, o uso do desenho como atividade foi importante para o processo de ensinagem sobre clima a utilização das paisagens feitas pelos estudantes, pois, além de aproximá-los do conteúdo, o professor ainda capta o conhecimento prévio que cada um detém sobre tempo meteorológico e clima e com isso, segue num processo de troca e ressignificação do conteúdo abordado.

\section{REFERÊNCIAS}

AFONSO, A. E.; ARMOND, N. B. Reflexões sobre o ensino de geografia física no ensino fundamental e médio. In: X Encontro Nacional de Prática de Ensino em Geografia, Porto Alegre. Anais do X Encontro Nacional de Prática de Ensino em Geografia, 2009, Porto Alegre. Anais...Porto Alegre: UFRGS, 2009, s/p.

BARBOSA, M. E.; OLIVEIRA, A. O. S. A. Climatologia e internet: análise e proposta metodológica para o ensino de geografia no ensino médio. Revista geonorte, v. 1, p. 108-120, 2012.

BERTRAND, G. Paisagem e geografia física global: esboço metodológico. Caderno de Ciências da Terra, n. 13, p. 1-27, 1971.

BOGDAN, R. C; BIKLEN, Sari K. Investigação qualitativa em educação: uma introdução à teoria e aos métodos. Portugal: Porto Editora, 1994.

CASTELlAR, S. (ORG). A Psicologia Genêtica e a Aprendizagem no Ensino de Geografia. In: Educação geográfica: Teorias e práticas docentes. $3^{a}$.ed. São Paulo: Contexto, 2014, p. 38-50 (Novas abordagens).

CASTELlAR, S.; VILHENA, J. Ensino de geografia. São Paulo: Cengage Learning, 2012. - (Coleção ideias em ação).

CAVALCANTI, L. de S. O ensino de Geografia na escola. São Paulo: Papirus, 2012.

CAVALCANTI, L. de S. A educação Geográfica e a formação de conceitos: a importância do lugar no ensino de Geografia. In: PEREIRA, M. G. $1^{\circ}$ ed. La Espesura del lugar: e reflexiones sobre el espacio el mundo educativo., 2009. p. $137-151$.

FORTUNA, D. da S. As Abordagens da Climatologia nas Aulas de Geografia do Ensino Fundamental (segundo segmento): primeiras impressões. In: IV Seminário de Pesquisadores do Instituto de Ciências da Sociedade e Desenvolvimento Regional (ESR). Universidade Federal Fluminense (UFF). 2011, Anais.. Campos dos Goytacazes (RJ). IV Seminário de Pesquisa do Instituto de Ciências da Sociedade e Desenvolvimento Regional (ESR), 2011, p. 1-10.

PEREIRA, C. M. R. B; DIAS, D. L. A representação da paisagem através do desenho. In: SACRAMENTO, A. C. R.; ANTUNES, C. da F.; SANTANA FILHO, M. M. de. (Org.). Ensino de geografia: produção do espaço e processos formativos. 1ed. Rio de Janeiro: CONSEQUÊNCIA/FAPERJ, 2015 , v. 1, p. 36-53.

SANTOS, M. A. dos. Como você conceitua as noções de urbanização e metropolização (entrevista). Revista Caramelo, São Paulo, n.7, p. 60-71, 1994. 